\title{
Design and Development of Weather Monitoring and Controlling System for a Smart Agro (Farm)
}

\author{
Sumya Tabassum, Afzal Hossain \\ Department of Computer Science and Engineering, World University of Bangladesh, Dhaka, Bangladesh \\ Email: sumaiyatabassum417@gmail.com,afzal2@csewub.edu.bd
}

How to cite this paper: Tabassum, S. and Hossain, A. (2018) Design and Development of Weather Monitoring and Controlling System for a Smart Agro (Farm). Intelligent Control and Automation, 9, 65-73. https://doi.org/10.4236/ica.2018.93005

Received: June 28, 2018

Accepted: August 14, 2018

Published: August 17, 2018

Copyright (c) 2018 by authors and Scientific Research Publishing Inc. This work is licensed under the Creative Commons Attribution-NonCommercial International License (CC BY-NC 4.0). http://creativecommons.org/licenses/by-nc/4.0/ (c) (i) (8) Open Access

\begin{abstract}
Weather plays an important role in our farming system. In greenhouse or internal farming system, weather monitoring is important. For better production and maintenance, it is important to monitor. This project is developed for forecasting weather parameters like humidity, temperature, soil moisture, and raid detection. Humidity and temperature are monitored for internal temperature. The soil is the most important part of a greenhouse. In this project, soil moisture level is monitored and controlled for maintaining soil moisture level. Rain detection is used in outside of the farm. It detects rainwater and sends a message to the server. It is monitored by using a local server. In remote routing area, it also can be monitored and controlled without physical existence. Also, it is a low-cost weather monitoring system for the agro farm. The Raspberry Pi is a low cost, credit-card sized computer that plugs into a computer monitor or TV, and uses a standard keyboard and mouse. The monitoring system could be designed by using the sensor. It is useful for forecasting and data analysis process. In this project weather forecasting system is designed by using a sensor. In this project, Raspberry Pi work like a remote monitoring and controlling system for the agro farm.
\end{abstract}

\section{Keywords}

Weather, Forecast, Monitor, Agro, Farm, Raspberry Pi, Sensor

\section{Introduction}

Weather describes the atmospheric condition at a place over a short duration of time. Weather is defining different variables, such as temperature, humidity, air pressure, and the wind. Weather or Climatic change plays an important role in 
human life.

Weather monitoring is important for our household, farming to the industrial environment. There has been always a huge importance of climate for human life and to develop agriculture to its observation. Nowadays, there are many automation systems and weather forecasting systems all over the world collecting the environmental parameter continuously for forecasting. Weather plays an important role in agricultural production. It has a profound influence on crop growth, development, and yields, on the incidence of pests and diseases, on water needs, and on fertilizer requirements. For more production, a farming system needs real-time monitoring and update of soil moisture, rain detection, and different data analysis [1]. The monitoring system could be design based on IoT by using Raspberry Pi [2].

The Raspberry $\mathrm{Pi}$ is a low cost, credit-card sized computer that plugs into a computer monitor or TV, and uses a standard keyboard and mouse. It is a capable little device that enables people of all ages to explore computing and to learn how to program in languages like Scratch and Python. It's capable of doing everything like a desktop computer to do, from browsing the internet and can be capable to maintain external device like Arduino.

For better production and harvesting rare crops and fruits, farming system needs real time weather update. This weather monitoring system can get update of temperature, humidity, soil moisture rate, and rain detection analysis. Sometime weather climates can change unfortunately or soil needs more water or remove water, so that this device can detect this problem and give update to farmer for quick solution. This proposed system has three sensors which can detect temperature, humidity, soil moisture, and rain detection measurement from analog to digital. Raspberry Pi will receive readings from various sensors and then process the data and then data will be available on pi monitoring system for viewing of user at remote location. This system also can control soil moisture and water supply system.

Monitoring system could be design by using sensor [3]. It is useful for forecasting and data analysis process. Processing, analysis and transfer of data is very important for aspect of measurement. The main aim of this paper is to design and develop a weather monitoring system using Raspberry Pi [4] [5]. This device or monitoring system fetches weather condition like temperature humidity, soil moisture and rain detection. Knowing the exact soil moisture conditions on their fields, not only are farmers able to generally use less water to grow a crop, they are also able to increase yields and the quality of the crop by improved management of soil moisture during critical plant growth stages. Among various technology of weather forecasting system, Raspberry $\mathrm{Pi}$ is the latest and effective remote technology. In Raspberry Pi it uses sensor for real time weather monitoring and can get update. The system function developed using python language. This project is useful for any user who wish to monitor the current weather condition of their farm or industrial location without being physically 
present.

\section{Objectives}

The objectives of the study are:

1) To develop an IOT based Weather Monitoring and Controlling system for a smart Agro (Farm).

2) To make an interface for maintaining and controlling the soil moisture rate of Agro farm.

3) To get the real time weather condition for a smart Agro system.

\section{Literature Review}

"Real Time Weather Monitoring from Remote Location Using Raspberry pi" proposed a system for Real time weather monitoring using Raspberry pi, it will measure various weather parameters like temperature, light intensity, atmospheric pressure, Gas/smoke level using appropriate sensors interfaced with Raspberry $\mathrm{Pi}$, it uses wireless technology to provide real time data transfer. The project deals with designing a simple, highly efficient, cost effective and easy to operate Real time weather monitoring system. Using a database to raspberry pi this project can access from anywhere (Vijayalakshimi, K \& Lakshmi, G.V, C 2016) [6].

"Raspberry Pi Based Weather Monitoring System" proposed a system that visualize the parameters of weather variables. To know the current weather condition at remote location this system is design for. Proposed System will visualize and store various weather parameters as given above with the help of sensors interfaced to Raspberry will get al data, SD card on Pi stores the collected data as like memory card (V. Rasal, M \& G. Rana, J, C 2016) [7].

"An Intelligent Weather Station" presented an intelligent weather station for forecasting different variables of weather. To predict and analysis weather variables from anywhere. The hardware and software design of the implemented prototype are described the forecasting performance related to the three atmospheric variables, atmospheric pressure, humidity, temperature (Mestre et al. 2015).

"Weather Monitoring Using Raspberry Pi Viva Web Application" proposed an environment monitoring system. This system also capable of monitoring and control of environmental parameters like temperature, pressure and humidity. It also focused on low cost. This system uses Wireless sensor Networks for sensing the environment parameters in the area under supervision (Vasantha, J \& Basha, M, 2016).

"Soil and water analysis techniques for agricultural production" proposed parameters used for the efficiency analyses in soil moisture levels. It also analysis the soil moisture level. In this paper, it discus about soil moisture, texture and average moisture value (Maral. N, 2010).

"An Effective Method for Soil Moisture Sensing using Arduino Uno and In- 
terfacing with GSM Sim900" proposed that soil sensors are used to measure the volume fraction of water in soil. A soil moisture sensor detects the water level and provides information to accordingly control the supply of water. Also, different crops require varying amounts of water for cultivation. Here it also measures the moisture value according to the water level (Panigrahy. A et al., 2016) [8].

“Arduino Based Automatic Plant Watering System" proposed that an artificial application of water to the land or soil. It is used to assist in the growing of agricultural crops, maintenance of landscapes, and revegetation of disturbed soils in dry areas. A high relative humidity (above $80 \%$ - 85\%) should be avoided because it can increase the incidence of disease and reduce plant transpiration. In that percentage of moisture water supply must be ignored (Devika. S et al. 2014) [9].

\section{Methodology}

Methodology is asset of ides or guidelines about the existing process. It is the process about how to collecting and validating knowledge of a subject matter.

Following is a diagrammatic representation of different phases of proposed methodology (Figure 1).

\section{Design and Development}

\subsection{System Design}

In this paper author want design the weather forecasting prototype system

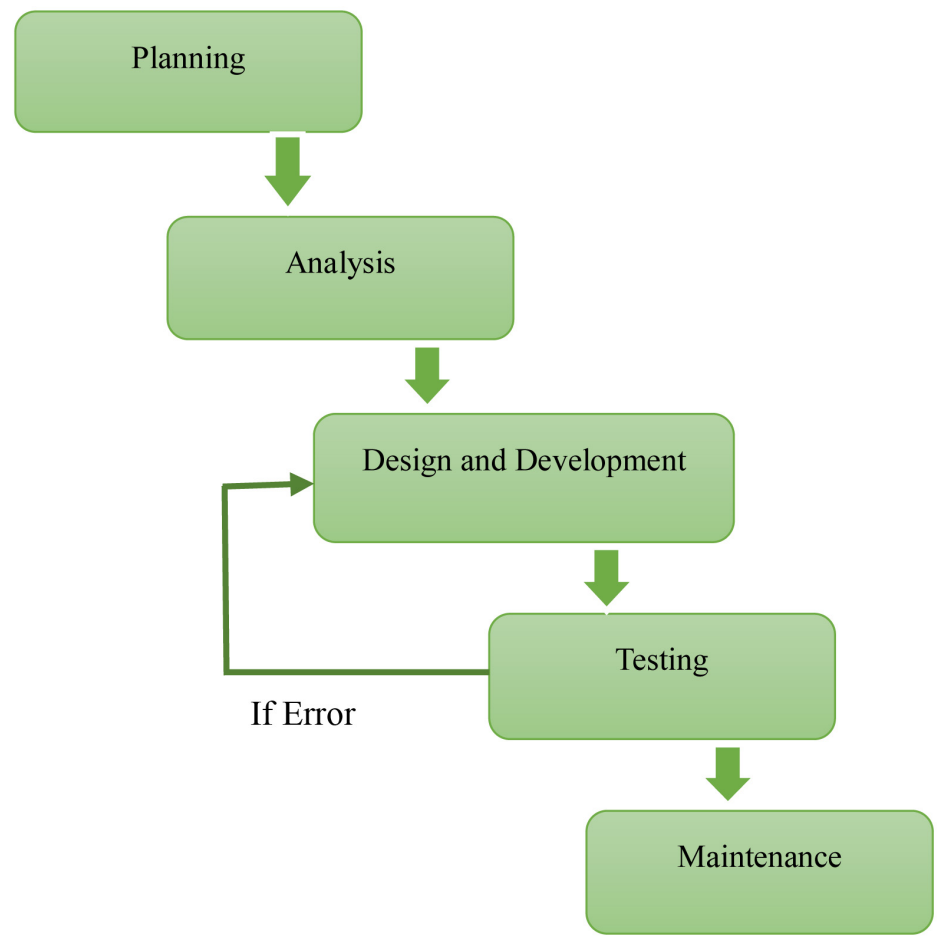

Figure 1. Block diagram of proposed model. 
developed for farming. Using relatively inexpensive component and sensor to develop this device. This prototype system can detect temperature, humidity, soil moisture, rain detector which could be monetarized from anywhere. It could be used for the agricultural land for the weather monitoring and viewed for productive statistical analysis (Figure 2).

\subsection{Description of Block Diagram}

Temperature humidity sensor send digital value and soil moisture sensor and rain detector sensor send analog value to Arduino. Arduino UNO send data to Raspberry Pi for process that value and store in local database system. Local database system store data and it also can access from remote routing area. It is eligible to access by using laptop or smartphone.

\subsection{Requirement Analysis}

Requirements analysis is the first stage in the systems engineering process and software development process. Requirements analysis is the tasks that an analyst performs to structure and organize requirements, specify and model requirements and

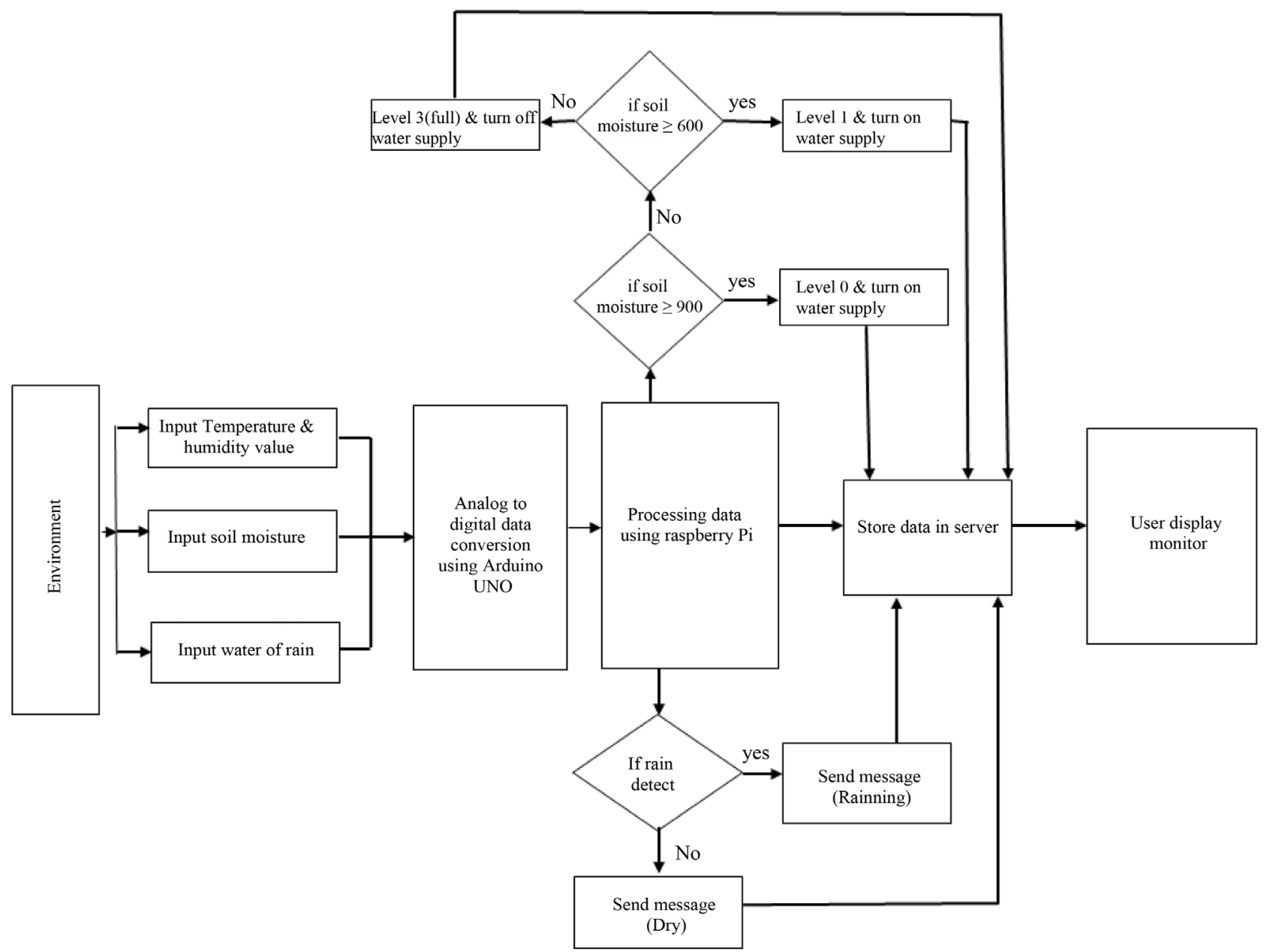

Figure 2. System design for iot based weather forecasting using raspberry pi. 
designs, validate and verify information, identify solution options that meet project needs, and estimate the potential value that could be realized for a solution option.

\subsubsection{Hardware Requirements}

Hardware requirement is the tasks that an analyst performs to design and solution option of system. This requirement fulfils the system design. In this project, different hardware is use for system design and development.

\subsubsection{Tools}

Following is a list of different tools of proposed project.

1) Raspberry Pi 3B

2) Arduino UNO

3) Temperature \& Humidity sensor (DHT-22)

4) Soil moisture sensor

5) Raid detector sensor

6) Motor

7) Router

\subsubsection{Software Requirements}

1) IDLE (python 2.6.)

2) Sqlite3

\subsection{Device Connectivity View for Proposed Model}

Please see Figure 3.

\section{Project Descriptions and Result}

\subsection{Demo Photo of the Project}

This system is shown a demo weather monitoring and controlling system for a smart agro farm (Figure 4).

\subsection{Project Description}

In this project, Raspberry pi work like a remote monitoring and controlling system

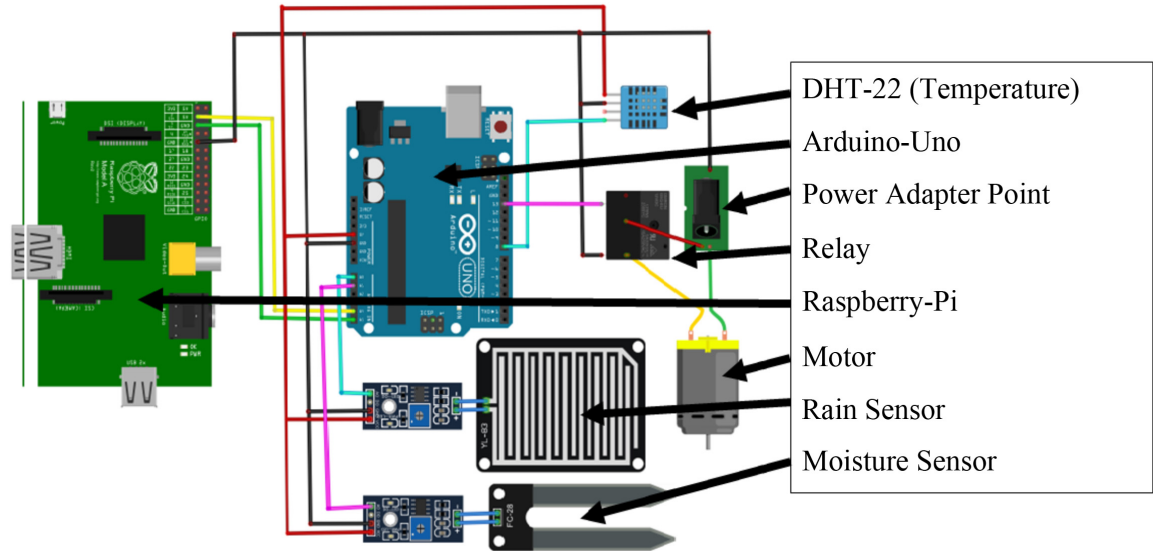

Figure 3. Connectivity view. 


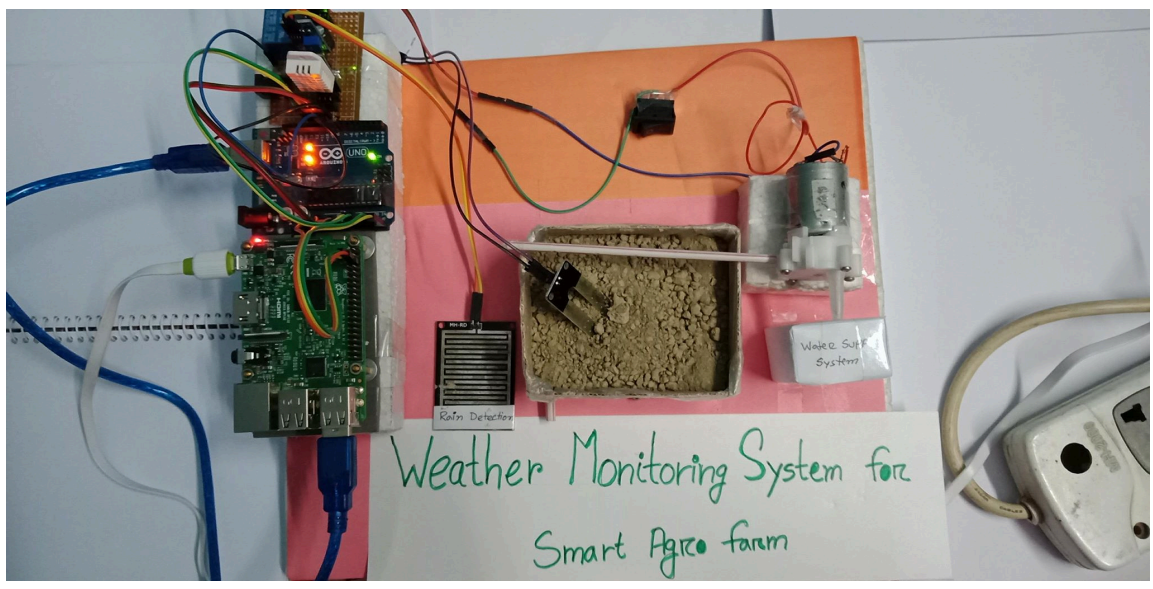

Figure 4. Demo photo of the project.

for a agro farm. Weather parameters like humidity temperature, soil moisture, rain detection is monitor for better performance and production. Arduino receive data from different sensor and send it to raspberry pi. Raspberry pi is received data using $\mathrm{i} 2 \mathrm{c}$ communication and process value using python language for monitor. Soil moisture is controlled by according their value of moisture level [7]. Soil moisture level is distributing with three level like full level, level 1 and level 0 . Here full level is defined that soil moisture is full, level 1 define that soil moister is not dry or not wet and level 0 define that soil is full dry. According to the level of soil moisture, raspberry pi is controlling the water supply. This overall process is stored in local server for monitor.

\subsection{Results of the Project and Automatic Soil Moisture Controlling and Rain Detection}

In this result, local server shown a smart agro farm weather monitoring system in 10 second time interval (Figure 5). It showed four parameters, humidity, temperature, soil moisture, rain detection (Figure 6).

\section{Conclusions}

\subsection{Conclusion}

This project is designed and developed for weather monitoring and controlling system. In the introduction, it describes the weather parameters and objectives of the project. It also describes the justification of project and working scopes in real life. In the literature review, few relevant works are describing this field. Methodology is all about the justification of all workflows. In this chapter, it describes the details about the system flow of this project. In design and development chapter, it describes the system design and hardware-software requirements. It also describes the connectivity diagram of the hardware system. Result chapter describes the output.

In this project, weather monitoring and controlling system are designed and developed for the agro farm. In farming, the weather is very important for better 


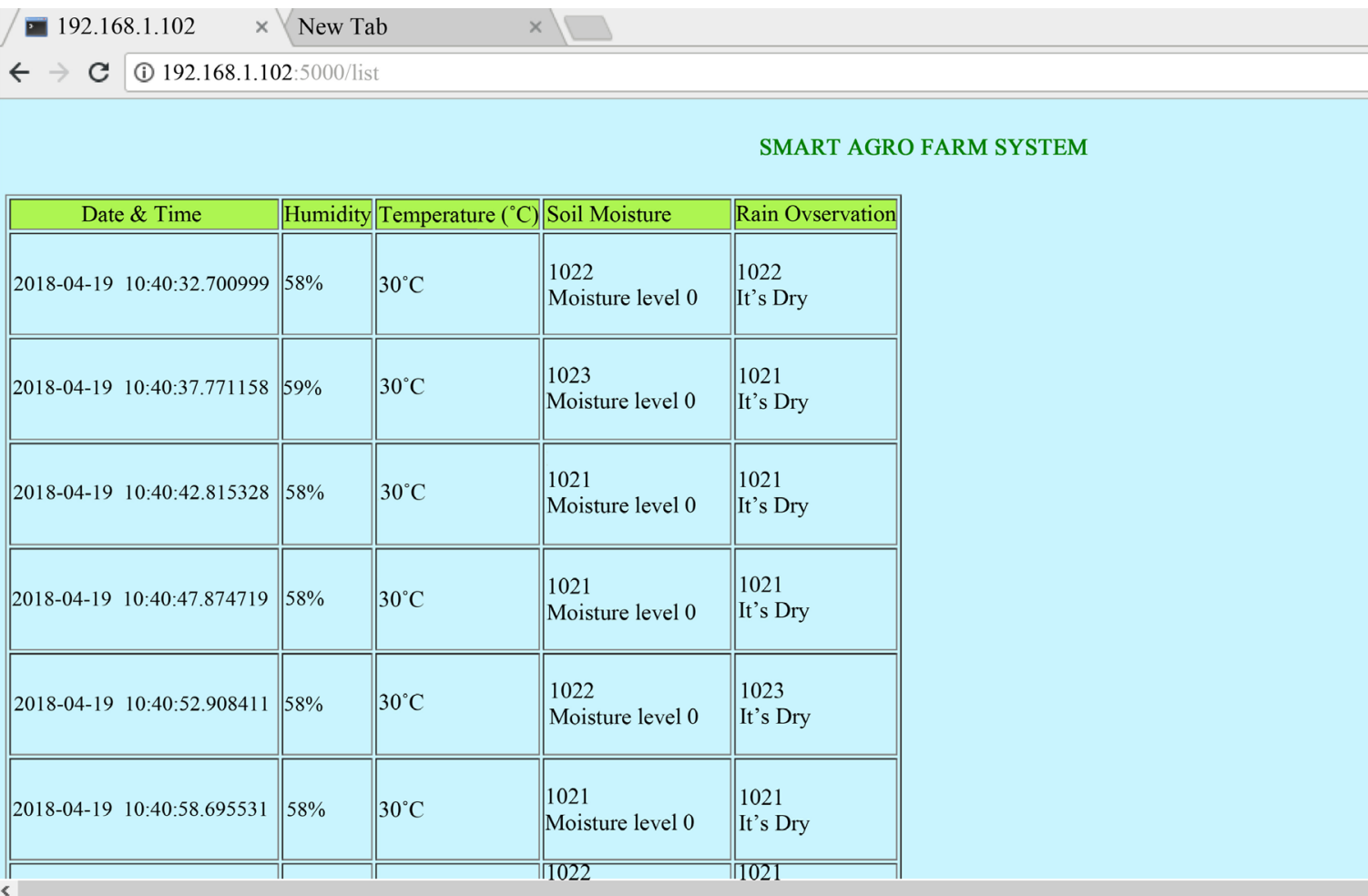

Figure 5. Output results of the project.

\begin{tabular}{|c|c|c|c|c|}
\hline 2018-05-13 18:09:54.885827 & $60 \%$ & $30^{\circ} \mathrm{C}$ & $\begin{array}{l}1003 \\
\text { Moisture level } 0\end{array}$ & $\begin{array}{l}247 \\
\text { It's Rainning }\end{array}$ \\
\hline 2018-05-13 18:10:04.957241 & $60 \%$ & $30^{\circ} \mathrm{C}$ & \begin{tabular}{|l}
1008 \\
Moisture level 0
\end{tabular} & $\begin{array}{l}483 \\
\text { It's Rainning }\end{array}$ \\
\hline 2018-05-13 18:10:15.616399 & $60 \%$ & $30^{\circ} \mathrm{C}$ & \begin{tabular}{|l}
1001 \\
Moisture level 0
\end{tabular} & $\begin{array}{l}505 \\
\text { It's Rainning }\end{array}$ \\
\hline 2018-05-13 18:10:25.687110 & $60 \%$ & $30^{\circ} \mathrm{C}$ & \begin{tabular}{|l}
999 \\
Moisture level 1
\end{tabular} & $\begin{array}{l}424 \\
\text { It's Rainning }\end{array}$ \\
\hline 2018-05-13 18:10:35.754428 & $60 \%$ & $31^{\circ} \mathrm{C}$ & \begin{tabular}{|l}
988 \\
Moisture level 1
\end{tabular} & $\begin{array}{l}234 \\
\text { It's Rainning }\end{array}$ \\
\hline 2018-05-13 18:10:45.832260 & $60 \%$ & $31^{\circ} \mathrm{C}$ & $\begin{array}{l}347 \\
\text { Moisture level is Full }\end{array}$ & $\begin{array}{l}181 \\
\text { It's Dry }\end{array}$ \\
\hline 2018-05-13 18:10:55.916154 & $60 \%$ & $31^{\circ} \mathrm{C}$ & $\begin{array}{l}310 \\
\text { Moisture level is Full }\end{array}$ & $\begin{array}{l}242 \\
\text { It's Rainning }\end{array}$ \\
\hline 2018-05-13 18:11:06.006169 & $60 \%$ & $30^{\circ} \mathrm{C}$ & $\begin{array}{l}320 \\
\text { Moisture level is Full }\end{array}$ & $\begin{array}{l}226 \\
\text { It's Rainning }\end{array}$ \\
\hline
\end{tabular}

Figure 6. Automatic soil moisture controlling and rain detection.

production and maintenance. This project is developed for forecasting weather parameters like humidity, temperature, soil moisture, and raid detection. It is monitored by using a local server. In remote routing area, it also can be moni- 
tored and controlled without physical existence. Also, it is a low-cost weather monitoring system for the agro farm.

\subsection{Future Works}

In future this project can be developed further and it can also give more effective result in real life application.

1) From one-week observation, the weather parameters value can be used for weather prediction for upcoming days.

2) Increasing sensor for more effective result.

3) To develop mobile application for forecasting weather from anywhere in the world.

\section{Conflicts of Interest}

The authors declare no conflicts of interest regarding the publication of this paper.

\section{References}

[1] Panigrahy, A., Chavan, S.S., Patil, R.N. and Vidyapeeth, B. (2016) An Effective Method for Soil moisture Sensing Using Arduino Uno and Interfacing with GSM Sim900. International Journal for Scientific Research \& Development (IJSRD), 4.

[2] Vasantha, J. and Basha, S.M. (2016) Weather Monitoring Using Raspberry Pi Viva Web Application. International Journal of Research (IJR), 03.

[3] VivekBabu, K., Reddy, K.A., Vidhyapathi, C.M. and Karthikeyan, B. (2017) Weather Forecasting Using Raspberry Pi With Internet of Things (IoT). ARPN Journal of Engineering and Applied Science, 12.

[4] Nguyen, H.-Q., Loan, T.T.K., Mao, B.D. and Huh, E.-N. (2015) Low Cost Real-Time System Monitoring Using Raspberry Pi. 2015 Seventh International Conference on Ubiquitous and Future Networks, Sapporo, 7-10 July 2015, 857-859. https://doi.org/10.1109/ICUFN.2015.7182665

[5] Savic, T. and Radonjic, M. (2015) One Approach to Weather Station Design Based on Raspberry Pi Platform. IEEE Sponsored 23rd Telecommunication Forum TEFLOR, Belgrade, 24-26 November 2015, 623-626. https://doi.org/10.1109/TELFOR.2015.7377544

[6] Vijayalakshimi, K. and Lakshmi, G.V.M. (2016) Real Time Weather Monitoring from Remote Location Using Raspberry Pi. International Journal of Advanced Research in Electrical, Electronics and Instrumentation Engineering (IJARCCE), 5.

[7] Rasal, M.V. and Jaideep, G. (2016) Raspberry Pi Based Weather Monitoring System. International Journal of Advanced Research in Computer and Communication Engineering (IJARCCE), 5.

[8] Shete, R. and Agrawal, S. (2016) Important Of Effective And Low-Cost Building Monitoring System (BMS) Using Raspberry Pi. Communication and Signal Processing (ICCSP), International Conference on IEEE, Singapore, April 2016, 2008-2012.

[9] Devika, S., et al. (2014) Arduino Based Automatic Plant Watering System. International Journal of Advanced Research in Computer Science and Software Engineering (IJARCSSE), 4, No. 10. 